\title{
RES, an expert system for the set-up and interpretation of a ruggedness test in HPLC method validation
}

\section{Part 2: The ruggedness expert system}

\author{
J.A. van Leeuwen *, L.M.C. Buydens, B.G.M. Vandeginste ${ }^{\star}$ and G. Kateman \\ Department of Analytical Chemistry, Catholic University Nijmegen, Toernooiveld 1, \\ 6525 ED Nijmegen (The Netherlands) \\ P.J. Schoenmakers \\ Philips Research, Prof. Holstlaan, 5656 AA Eindhoven (The Netherlands) \\ M. Mulholland \\ Philips Scientific, York Street, CB1 2PX Cambridge (U.K.)
}

(Received 21 March 1990; accepted 6 October 1990)

\begin{abstract}
Van Leeuwen, J.A., Buydens, L.M.C., Vandeginste, B.G.M., Kateman, G., Schoenmakers, P.J. and Mulholland, M., 1991. RES, an expert system for the set-up and interpretation of a ruggedness test in HPLC method validation. Part 2: The ruggedness expert system. Chemometrics and Intelligent Laboratory Systems, 11: 37-55.

An expert system is described for the design and diagnosis of the results of a ruggedness test in HPLC method validation. It advises on the selection of relevant factors and an appropriate experimental design and it translates the statistical results into chemically relevant results. If the test fails, the program can advise on how to improve the HPLC method. The basis of the program is a Common Data Structure which represents all objects that are important in HPLC. Linked to this Common Data Structure are modules that manipulate objects. The modules represent major steps in a ruggedness test. An expert system on factor choice and a program on solving resolution problems are integrated in this program as modules. The program is designed to advise on a complete ruggedness test, from factor choice to improvement of the method.
\end{abstract}

\section{INTRODUCTION}

The traditional emphasis in chemometric research has been on the application of statistics

\footnotetext{
* Present address: Unilever Research Laboratory, Vlaardingen, The Netherlands.
}

and multivariate analysis to chemistry. Recently techniques from artificial intelligence, specifically expert systems, have been introduced into chemometrics. Expert systems can represent the knowledge of an experienced worker. This heuristic knowledge, which is based on experience accumulated during practical work, is often not yet 
supported by a good theoretical model. Therefore, heuristic knowledge cannot usually be formalised into algorithms, making it difficult to include heuristics in conventional algorithmic software. As a consequence, heuristic knowledge is not as widely used as knowledge that is implemented in an algorithm.

Heuristic knowledge, such as the knowledge of when and how to use a particular technique, is required in chemometric procedures. In general, the use of chemometrical techniques requires a certain amount of experience in this field before the techniques can be applied with success. Expert systems offer the possibility to introduce chemometrical techniques, such as multivariate analysis and statistical techniques, into the laboratory. They reduce the necessity to train laboratory staff, because the programs already contain the knowledge of an experienced worker. Because of the complexity of chemometric techniques, training is usually a bottleneck in the introduction of chemometrics. In chemometrics, techniques are also used from other fields of science, in which analysts have little background.

A typical example of this type of problem is statistical testing. The decision on when to use a specific technique and the set-up of an appropriate test can be very difficult. Various aspects, such as the purpose of the test, the available time or manpower, etc. have to be taken into account before deciding on the use of a certain experimental design. The translation of the results of statistical processes into chemically relevant results usually also requires specialists. Expert systems can improve this situation. They provide the analyst with the necessary statistical procedures, with knowledge on how to set up the statistical tests and with knowledge on how to translate the statistical data into chemical results. An ideal expert system will only need an adequate description of the problem to be solved to come to a valid conclusion or advice.

In this paper an expert system is described that guides a user through a ruggedness test in highperformance liquid chromatographic (HPLC) method validation. The theory that is contained in this program is described in Part 1 of this work [1]. The purpose of the research presented here is to demonstrate the possibility of using expert systems in HPLC method validation. The expert system has been developed as part of a larger project, in which similar programs have been developed for other parts of HPLC method development [2-4]. The aim of the expert system is to guide a user through a complete ruggedness test, from the set-up of the test to the interpretation of the results. Therefore, this system must be able to perform various types of tasks, including planning, diagnosis and calculation.

\section{EXPERT SYSTEMS}

The knowledge domain of the first generation of expert systems emerging in chemistry was not chemometrics. The majority of these first generation expert systems were rule-based [5-11]. As a consequence only limited types of knowledge were represented. Rules are only suitable for representing heuristic knowledge found in diagnostic processes, such as spectrum interpretation. Thus, the interpretation of spectra obtained in NMR, IR, mass spectroscopy, etc. was the area in which most of the first generation expert systems were developed [12-23].

Knowledge on setting up and interpreting experiments is different. For instance, algorithms and strategic knowledge also play an important role. However, these types of knowledge cannot always be efficiently represented in rules. Therefore, an expert system in this domain must be a hybrid system, which employs more than one knowledge representation technique.

Moreover, rule-based systems lack good facilities for structuring. As a consequence, the size of the knowledge base in rule-based systems is limited. However, an expert system on the planning of experiments and the interpretation of the results is likely to be large, because it covers a number of different areas.

The lack of structuring makes it difficult to keep good overview of the knowledge in a rulebased system, necessary to make changes. Adaptions of the knowledge base may have unpredictable effects on the performance of the expert system. In many application areas, however, the 
possibility to make changes to the knowledge base is important. For instance, every laboratory applies its own strategy for setting up experiments and will only accept an expert system if it reflects this strategy. If it does not, it is important that the user has a (limited) access to the knowledge and is allowed to implement small changes. For instance, if the system proposes a certain experimental design, the user should have the possibility to replace it by another. Incorporating such possibilities requires an open and flexible architecture of the expert system. In the present paper an example is given of an expert system that does have such flexibility. It contains knowledge about ruggedness testing in HPLC method validation. The program advises the user on the set-up of the test, provides the possibility to process the experimental data and to interpret the data to come to an advise on how to proceed, based on the results of the test.

The architecture of the program allows a combination of different knowledge representation techniques. This opens up the possibility to include algorithms and heuristics in a single program. The architecture also facilitates the addition of new knowledge to the system without having to change its structure. The knowledge in the system is split into modules dedicated to specific tasks,

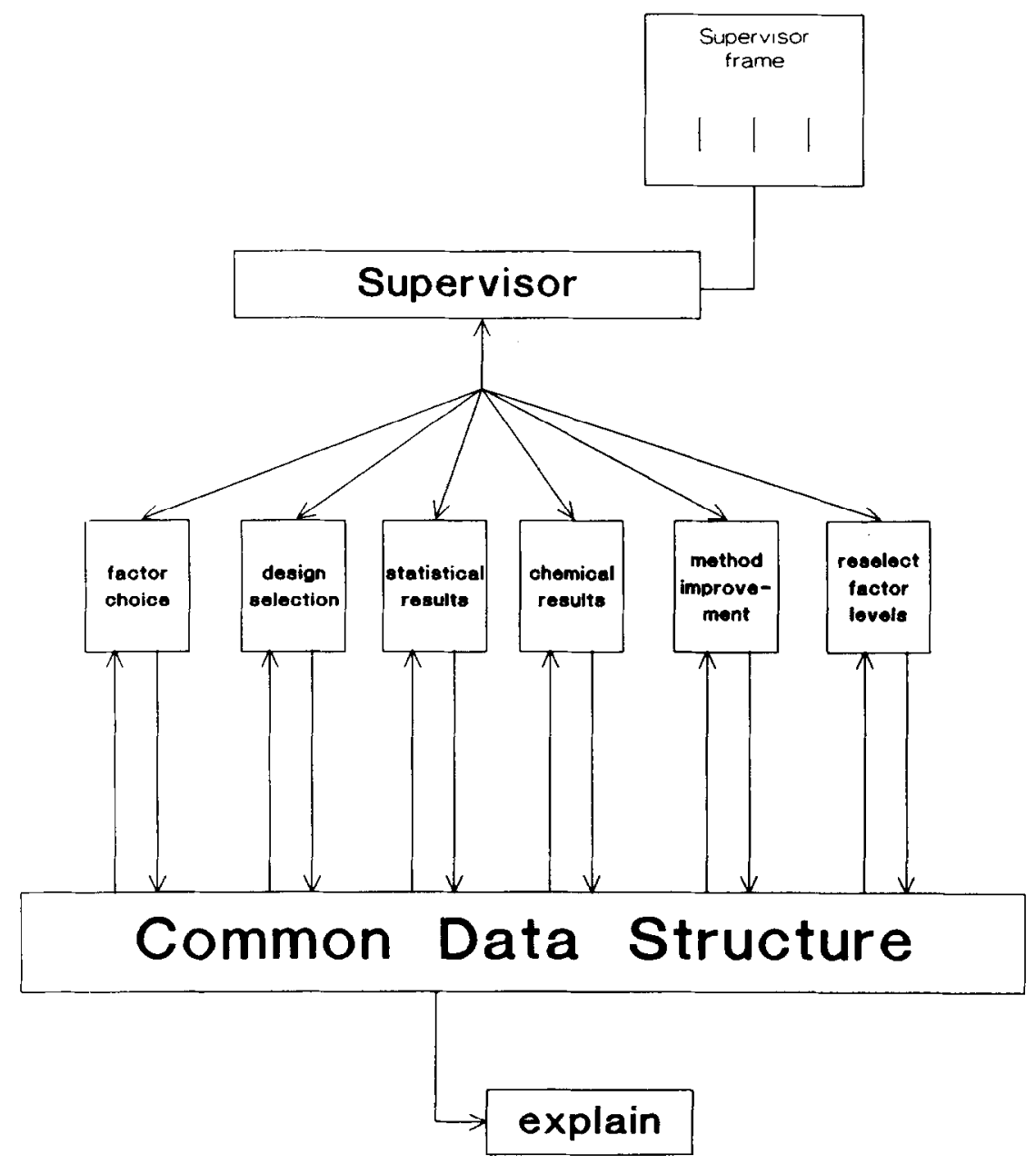

Fig. 1. The structure of RES. 
and general knowledge, available to all modules in the system. This feature allows the user to add his own knowledge to the system by adding modules. Also, the existing modules are structured so as to allow small changes to be made. Typical features of the architecture are a Common Data Structure containing all general knowledge and a Supervisor to control the modules.

RES

RES (Ruggedness Expert System) consists of six modules that represent the major steps in the set-up and interpretation of the ruggedness test (Fig. 1) [1]. Each module is designed to perform one step in the ruggedness test.The modules use different inference techniques and knowledge representation methods. They are designed for use as stand-alone units, and to serve as part of an integrated system.

The modules are controlled by a supervisory system that can activate or deactivate them, depending on the situation. The Supervisor contains knowledge on when to activate which module, although this can also be user controlled. The Supervisor only activates the modules, it does not interact with the processes taking place within the modules.

A data base has been constructed for the communication between the modules. Because it not only contains data, but also relations between the data, it is called the Common Data Structure. The Common Data Structure will accommodate all data produced by the modules. It has no effect on how the modules produce the data.

The architecture used for RES is intended to be flexible and easily adaptable. New modules can be added, provided that an interface is built to the Common Data Structure. To demonstrate this possibility two existing systems on factor choice and method improvement have been incorporated into RES.

The modular structure of RES also makes it possible to change the contents of one module without having to go through extensive testing procedures for the entire system. If the changed module performs well as a stand-alone system, it will also perform well in the integrated system. In RES, a stand-alone system is a module using (part of) the Common Data Structure. Sometimes it may also be necessary to include aspects of the Supervisor in a stand-alone system for user-interfacing purposes.

\section{HARDWARE AND SOFTWARE}

RES consists of eight parts (six modules, the Common Data Structure and the Supervisor) that work in close coherence. The two algorithmic parts (the statistical results module and the method improvement module) are programmed in $\mathrm{C}$ (MicroSoft $\mathrm{C}$ version 5.1). The other parts are programmed in the expert system development tool Goldworks (version 1.1).

The hardware used is an IBM PC AT with 8 $\mathrm{Mb}$ extended memory. The original oscillator of 6 $\mathrm{MHz}$ has been replaced by one of $10 \mathrm{MHz}$. This reduced the longest waiting time during consultation of the system to 5 minutes or less.

\section{The modules}

The modules contain the expert knowledge of the program. Each module represents and performs a well-defined step in the ruggedness test [1]. Each module has been implemented using the most appropriate representation technique for its task. Hence, steps that depend heavily on the experience of the person performing them are implemented using a heuristic representation technique such as rules. The factor choice module is a typical example. Steps for which good algorithms exist, such as the statistical evaluation of the experimental results, have been implemented in conventional algorithmic programming languages.

\section{The factor choice module}

The factor choice module selects the factors to be included in the ruggedness test and the factor levels. It is a rule-based module, divided in rule sets representing the underlying procedures in the HPLC method. The factor choice module has been developed as a stand-alone expert system [24]. 
The input into the factor choice module consists of a description of all the relevant parts of the HPLC method to be tested. This description includes information on the chromatograph, the column, the detectors, etc. Using the appropriate rules, the module generates a number of factors that will be included in the ruggedness test (sce Appendix A2 for an example of input information).

In the factor choice module, a distinction is made between two types of factors, numerical factors and drift factors. Numerical factors are factors that can vary on a continuous scale in infinitive small steps e.g. temperature or flow rate. Discrete factors can only vary in discrete steps e.g. batch of column packing material or the attenuation of the detector.

\section{TABLE 1}

List of designs incorporated in RES

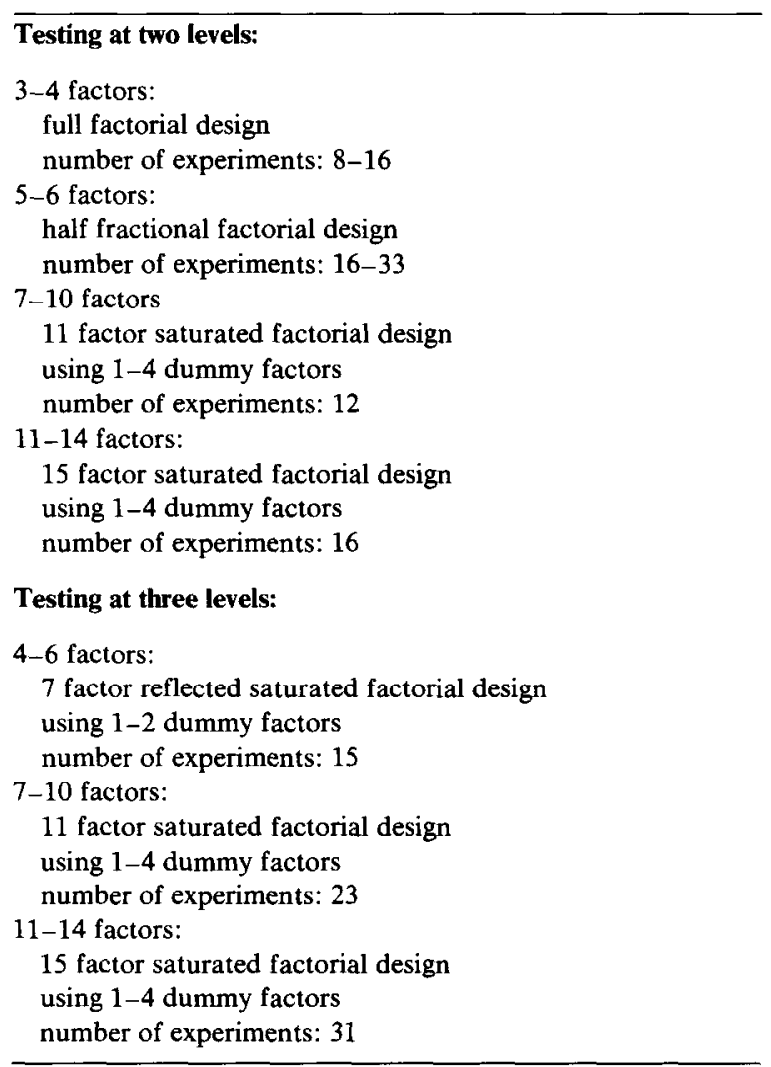

The choices of the factor levels differ for numerical and discrete factors. For numerical factors, the levels are expressed in percentages of the nominal level e.g.: vary temperature by + and $-10 \%$. For discrete factors, the factor levels are expressed in a step size variations from the nominal lcvel. For instance, the levels of the factor wavelength of the detector are expressed in steps of 10,5 or $3 \mathrm{~nm}$.

Some factors require special attention because they can drift during the experimental work; for instance, temperature or solvent composition due to evaporation. The factor choice module identifies the drift factors and flags them as they need special attention in the interpretation.

The factors are presented to the user with their nominal levels, the upper and lower levels at which they will be tested and the units in which the factor values are expressed. The user can overrule the decision of the expert system, using the factor edit facility (see Appendix A3), e.g. factor levels can be changed, or factors can be added or deleted. The system will keep track of the modifications made by the user and if necessary, the system's factor selection an be restored.

\section{The design selection module}

RES primarily bases its selection of an experimental design on the number of factors and the number of levels ( 2 or 3 ) that will be tested in the ruggedness test. The number of factors determines whether a full factorial design or a fractional factorial design will be used. If the number of factors is between 5 and 15 , a fractional factorial design is recommended. If a fractional design is used, the number of levels for each factor is normally three, unless the user has explicitly stated that only two levels should be tested. The choice of a design then changes slightly, especially if three to six factors are tested (Table 1). If all factors are tested at two levels, a larger experimental design can be used without increasing the number of experiments too much. If a single factor cannot be tested at more than two levels, it will be included in the design with all other factors at three levels.

The module may include a number of dummy factors in the design. Dummy factors can be used 


\section{TABLE 2}

The design and factors output file

Precision testing HPLC-method expert system

Version 3.0

Date:

Id. :

\section{Experimental setup}

$F 1==>$ factor 1

Exp-1 $==>$ experiment 1

$0 \quad=>$ nominal level

$1==>$ upper level

$-1==>$ lower level

$==>$ no second level $->>$ test at nominal level

F1 : Factor nominal-level upper-level lower-level

F1 : DUMMY-FACTOR-3

F2: DUMMY-FACTOR-2

F3 : DUMMY-FACTOR-1

F4: DATA-HAND

F5 : TIME-CONSTANT

F6: WAVELENGTH

F7: MANUFAC

F8: $\mathrm{PH}$

F9: ADDITIVE

F10: SOLVENT

F11 : SONICATE

$\begin{array}{lll}\text { SELECTED } & \text { *SELECTED } & \text { *SELECTED } \\ 0.5 & 1 & 0.1 \\ 205 & 210 & 200 \\ \text { SPHERISORB } & \text { OTHER } & \text { OTHER } \\ 7 & 8 & 6 \\ 1 & 1.5 & 0.5 \\ 50 & 53 & 47 \\ 10 & 12 & 8\end{array}$

Selected design : REFLECTED-SATURATED-FACTORIAL-DESIGN Divisor design : 6

$\begin{array}{lrrrrrrrrrrr} & \text { F1 } & \text { F2 } & \text { F3 } & \text { F4 } & \text { F5 } & \text { F6 } & \text { F7 } & \text { F8 } & \text { Fy } & \text { F10 } & \text { F11 } \\ \text { Exp-1 } & 1 & 0 & 1 & 0 & 0 & 0 & 1 & 1 & 1 & 0 & 1 \\ \text { Exp-2 } & 1 & 1 & 0 & 1 & 0 & 0 & 0 & 1 & 1 & 1 & 0 \\ \text { Exp-3 } & 0 & 1 & 1 & 0 & 1 & 0 & 0 & 0 & 1 & 1 & 1 \\ \text { Exp-4 } & 1 & 0 & 1 & 1 & 0 & 1 & 0 & 0 & 0 & 1 & 1 \\ \text { Exp-5 } & 1 & 1 & 0 & 1 & 1 & 0 & 1 & 0 & 0 & 0 & 1 \\ \text { Exp-6 } & 1 & 1 & 1 & 0 & 1 & 1 & 0 & 1 & 0 & 0 & 0 \\ \text { Exp-7 } & 0 & 1 & 1 & 1 & 0 & 1 & 1 & 0 & 1 & 0 & 0 \\ \text { Exp-8 } & 0 & 0 & 1 & 1 & 1 & 0 & 1 & 1 & 0 & 1 & 0 \\ \text { Exp-9 } & 0 & 0 & 0 & 1 & 1 & 1 & 0 & 1 & 1 & 0 & 1 \\ \text { Exp-10 } & 1 & 0 & 0 & 0 & 1 & 1 & 1 & 0 & 1 & 1 & 0 \\ \text { Exp-11 } & 0 & 1 & 0 & 0 & 0 & 1 & 1 & 1 & 0 & 1 & 1 \\ \text { Exp-12 } & 0 & 0 & 0 & 0 & 0 & 0 & 0 & 0 & 0 & 0 & 0 \\ \text { Exp-13 } & -1 & 0 & -1 & 0 & 0 & 0 & -1 & -1 & -1 & 0 & -1 \\ \text { Exp-14 } & -1 & -1 & 0 & -1 & 0 & 0 & 0 & -1 & -1 & -1 & 0 \\ \text { Exp-15 } & 0 & -1 & -1 & 0 & -1 & 0 & 0 & 0 & -1 & -1 & -1 \\ \text { Exp-16 } & -1 & 0 & -1 & -1 & 0 & -1 & 0 & 0 & 0 & -1 & -1 \\ \text { Exp-17 } & -1 & -1 & 0 & -1 & -1 & 0 & -1 & 0 & 0 & 0 & -1 \\ \text { Exp-18 } & -1 & -1 & -1 & 0 & -1 & -1 & 0 & -1 & 0 & 0 & 0 \\ \text { Exp-19 } & 0 & -1 & -1 & -1 & 0 & -1 & -1 & 0 & -1 & 0 & 0 \\ \text { Exp-20 } & 0 & 0 & -1 & -1 & -1 & 0 & -1 & -1 & 0 & -1 & 0 \\ \text { Exp-21 } & 0 & 0 & 0 & -1 & -1 & -1 & 0 & -1 & -1 & 0 & -1 \\ \text { Exp-22 } & -1 & 0 & 0 & 0 & -1 & -1 & -1 & 0 & -1 & -1 & 0 \\ \text { Exp-23 } & 0 & -1 & 0 & 0 & 0 & -1 & -1 & -1 & 0 & -1 & -1\end{array}$


to get an indication of possible interactions between factors. A thorough discussion of the theory and use of experimental designs has been presented by Deming and Morgan [25] and Massart et al. [26].

The experimental design is selected from a set of designs stored in the module (Table 1). However, the user can select other designs, e.g. if the user prefers to carry out less experiments. For this purpose, a design editor is available (see Appendix A4), which may require some file operations.

The module on selecting the experimental de- sign is a rule-based module. This rule-based representation facilitates the addition of new designs to the system by the user and the implementation of strategies on when to use the new designs. These strategies can be implemented as rules.

\section{Experiments}

After consultation of the factor and design selection modules, factors and factor levels and the experimental design are stored in a file for inspection by the user (Table 2). With the information in this file, the user can perform the experimental work and measure the necessary experimental parameters. RES can handle up to seven experimental parameters [1].

The experimental results must be presented to RES in a file with a special format. This file can be obtained from the instrument or other data processing software by simple conversion.

\section{The statistical results module}

The statistical results module of RES contains the algorithm to calculate the standard errors and main effects [1]. This module is implemented in C as it requires many calculations and a dynamic use of arrays. The experimental data are read from a file into the module (see Appendix A5). Calculated standard errors and main effects are written to files for inspection by the user. Also, intermediate results such as the differences and averages of the duplicates are written to a file. The intermediate results can provide useful information to the user if problems occur which the system cannot solve.

The module checks the levels of the main effects and standard errors. If either of these exceed a user specified level for any of the parameters considered, the experiment number and the component at which the standard error was outside the specified range are listed in a file for use by the chemical results module.

The statistical results module also provides system suitability criteria, which are only meaningful if all main effects and standard errors are within specifications.

\section{The chemical results module}

The chemical results module contains heuristic knowledge which is manipulated by object oriented programming in frames. The central objects in this module are the main effects and standard errors. The module attaches warnings to the objects by calling specific procedures that contain the actual knowledge.

The input of the module is a list of main effects and standard errors, which are compared with predefined criteria. On that basis it is decided whether they are relevant or not. The module informs the user which specific main effects and standard errors are not acceptable and it lists the peak number, the parameter affected, and the factor causing the violation (see Appendix A6). If resolution is the parameter for which a large main effect was found, it also calculates the difference between the observed resolution and the critical resolution.

The output of the module consists of a set of warnings that should be included in the final method description [1]. The diagnosis module also decides whether one of the repair modules should be activated. Depending on the cause of the problems, the system can activate two types of repair actions implemented in the method improvement module and the reselect factor levels module (see Appendix A8). Also, the user is informed on problems that could not be solved by RES.

\section{The reselect factor levels module}

The reselect factor levels module is a rule-based module that modifies the factor levels to a narrower range. Basically, it is a modified version of the rule set on factor selection with the difference that the factors to test are already known. This 
rule set, therefore, only contains the rules to find the levels. The input of this module are the factors that caused a main effect or standard error. These factors were listed for modification of the factor levels. The module produces a list of factors and levels that can serve as a new input to the design selection module to repeat the ruggedness testing procedure.

\section{The method improvement module}

The method improvement module is an algorithmic module that advises on improving the initial resolution of the method. This module, the so called SOS (System Optimisation System) module, has been derived from already existing software [2]. It has been integrated in the ruggedness system, while leaving it intact as much as possible, thus demonstrating that it is possible to add new knowledge to the system without changing its structure.

The purpose of this module is to increase the initial resolution between a critical pair of peaks if, during the ruggedness test, the resolution falls below a critical level. The module uses a database of columns and detectors specified by the user. In the database, the user can include all columns and detectors available and he can specify whether they are available for the method under investigation. The module calculates the effect of all possible combinations of columns and detectors with the specified instrumental conditions and advises the user to use a different flow rate, column or detector. The advice is based on the initial chromatogram, the flow rate, column and detector and on an estimate of the required resolution (see Appendix A7). The resulting method should undergo a new ruggedness test to check whether the problem has been solved. Therefore, the user has the possibility to copy the method to the method description part of the factor choice module and start a new ruggedness test.

\section{The Common Data Structure}

The modules in RES can access all data available in the system at any time. The modules will normally use only a limited part of the data avail- able. However, they share considerable parts of the data with other modules. Instead of defining for every module the exact data to which it has access and developing interfaces for the data to which mutual access is necessary, it is more efficient to make all data available for all modules at the same time. This flexible data structure will also allow additions to the system with a minimum of effort.

It is important that the modules obtain data that are up to date. Otherwise, inconsistencies may arise in the system, resulting in unreliable conclusions. If all modules use the same data and only one module can read or write data at the same time, inconsistencies will not occur.

To fulfil these two requirements, a Common Data Structure has been developed that contains all the objects used in the program. These objects range from physical objects such as an instrument or a column, to numerical objects, such as main effects or standard errors, and mental objects, such as warnings.

The objects are represented in frames to form Object-Attribute-Value triplets. This is a convenient representation technique, because it is flexible and allows object oriented programming. In a frame the features of an object are defined. By attributing values to the features, a specific instance of the object can be defined.

Relations between objects or attributes of objects can be represented using procedures. If, for instance, the value of a certain attribute determines the value of other attributes, a procedure can be attached to the first attribute to fill in all the dependent attributes each time the value of the first one changes.

The relations between the objects in the Common Data Structure organize the frames in networks, which are grouped to correspond to a certain module. As a consequence, there are factor frames, experimental design frames, diagnosis frames, etc. The most important network is the method description network, which is related to all the modules. The method description contains the information entered by the user when starting a consultation. The subsequent consultation is based on it and no further input is required from the user, except entering the experimental results. 


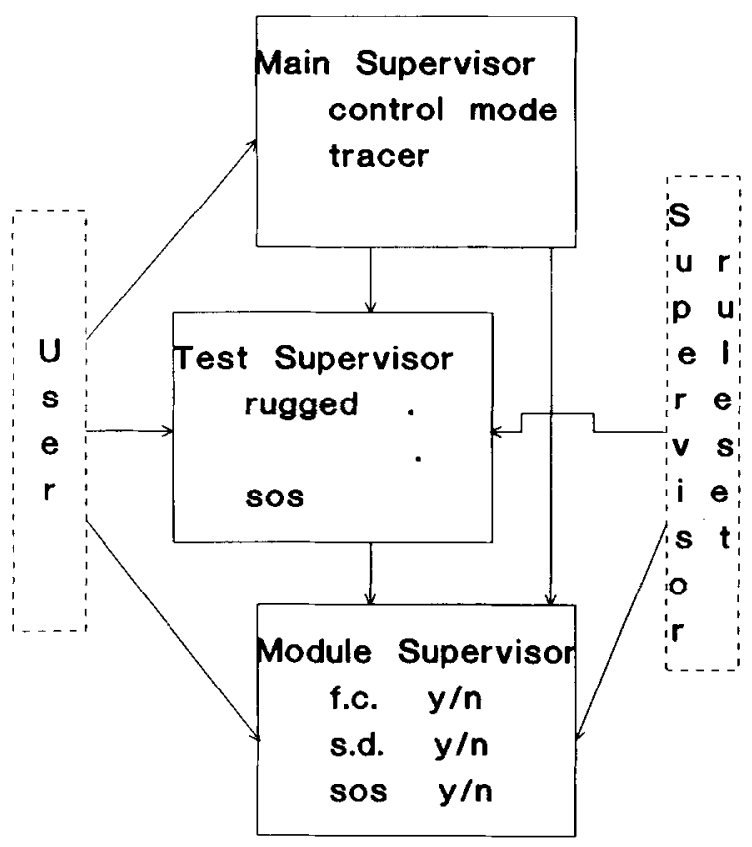

Fig. 2. The Supervisor structure.

\section{The Supervisor}

A supervisor structure controls the system. The Supervisor operates at three levels, implemented in threc frames (Fig. 2). The frames can interact with each other, with the user and with a rule set that contains knowledge on how to manipulate the frames. The Supervisor has been designed in three levels, to distinguish between the three types of operations that the Supervisor can support.

At the user interaction level, the highest level of the Supervisor, the Supervisor can be set to a number of modes. The most important mode is the control mode. The Supervisor contains a rule set in which knowledge is stored about the process of ruggedness testing, for example on when to use a ruggedness test. At the user interaction level, the supervisor rule set can be activated. If not, the user must select manually which modules he wants to use during the consultation. If the Supervisor is used, five input values on the expected usage of the method have to be specified, such as the number of laboratories or the number of analysts using the method. The input values are transferred to the Common Data Structure.
Another option in the Supervisor gives the user the possibility to interrupt the consultation after each module that has been consulted. This option is useful if the experimental work will take several days. The consultation will be stored to disk making the computer available for other tasks.

To assist in the validation of some of the modules a rule tracer option can also be activated in the Supervisor. This tracer produces a record of all the rules fired during a consultation. The tracer option is useful for debugging activities. It is limited to the rule-based modules.

At the second supervisor level, the modules are grouped into certain main operations. In RES only two such main operations exist, ruggedness testing and optimisation. Optimisation consists of only one module, the SOS module. Ruggedness testing consists of all the other modules. The operations level has primarily been provided to allow new operations, groups of modules, to be added without loosing the overview over the modules. The Supervisor has also been constructed independently from the Common Data Structure, allowing new levels to be added.

At the lowest supervisor level, the module level, the Supervisor (or, if necessary, the user) has access to all the individual modules. They can be activated or deactivated in any order.

\section{VALIDATION OF THE SYSTEM}

The evaluation of expert systems is a wellknown problem in artificial intelligence and software engineering. The main problems is the impossibility to define what a 'good' result is. Generally, good results are those that cause the user to benefit from the system. This means that the results produced by the program are useful in practice. However, this does not require that the program produces 'the best possible' result. In many cases, it is very difficult to select the best result. For instance, in the diagnosis module many assumptions had to be made. For example, how large can a main effect be before it becomes unacceptable? It is possible in some case that RES will advise to respecify the factor levels and to repeat the ruggedness test. If the method were to 
fail the ruggedness test again, then this advice was probably not the best possible. However, it may have been acceptable in the context of the first failure, because there was a reasonable chance of the method passing the test after respecification. The only good evaluation strategy for expert systems existing at the moment, is to use them in practice and to perform a practical evaluation of the results produces by the program.

However, before evaluation in practice can take place the program must be validated. The purpose of validation is to establish whether the program performs to the expectations of its makers. Validation involves the use of simulated data and an occasional real dataset. For the validation of RES some real test cases were used, supplemented by simulated test cases for the areas not covered by the real data. For both the real data and the simulated data the desired output of RES was known.

The factor choice module has been validated using 11 test cases. As this module is typically heuristic in nature, it is difficult to estimate its performance. In this case, the expert was given 11 method descriptions and was asked to select the factors that would have to be tested in a ruggedness test. The same method descriptions were entered into the program and the results were compared (Appendix B). The factor choice module appeared to have a $80 \%$ success rate [27].

The same 11 test cases that were used for validating the factor choice module were also used to test the design selection module. The same score of $80 \%$ success was reached for this module (Table 3) [27].

The statistical results module is primarily of an algorithmic nature. There are a number of methods to test algorithmic software [28]. In this case, a number of datasets were generated, which should not lead to any statistically relevant main effects. After these had been used to test the system, in each of them a number of disturbances was introduced resulting in significant main effects. Approximately 50 datasets have thus been processed by the statistical results module and the predicted main effects have been reflected correctly in the results obtained from the module.

The chemical results module has been imple-
TABLE 3

Test case results on the design selection

\begin{tabular}{|c|c|}
\hline $\begin{array}{l}\text { Test } \\
\text { case }\end{array}$ & Sample name \\
\hline 1 & $\begin{array}{l}\text { Salbutamol } \\
\text { expert: } 11 \text { factor reflected saturated factorial } \\
\text { expert system: idem }\end{array}$ \\
\hline 2 & $\begin{array}{l}\text { Imaprinine } \cdot \mathrm{HCl} \\
\text { expert: full factorial } \\
\text { expert system: } 7 \text { factor saturated fractional factorial }\end{array}$ \\
\hline 3 & $\begin{array}{l}\text { Fat soluble vitamins } \\
\text { expert: } 4 \text { factor half factorial } \\
\text { expert system: } 7 \text { factor fractional factorial }\end{array}$ \\
\hline 4 & $\begin{array}{l}\text { Steroids by fast } \mathrm{LC} \\
\text { expert: } 11 \text { factor reflected saturated factorial } \\
\text { expert system: idem }\end{array}$ \\
\hline 5 & $\begin{array}{l}\text { Corticosteroids } \\
\text { expert: } 7 \text { factor reflected saturated factorial } \\
\text { expert system: idem }\end{array}$ \\
\hline 6 & $\begin{array}{l}\text { Contraceptive tablet } \\
\text { expert: } 7 \text { factor reflected saturated factorial } \\
\text { expert system: idem }\end{array}$ \\
\hline 7 & $\begin{array}{l}\text { Anti-inflammatory drugs } \\
\text { expert: } 11 \text { factor reflected saturated factorial } \\
\text { expert system: } 7 \text { factor reflected saturated factorial }\end{array}$ \\
\hline 8 & $\begin{array}{l}\text { Chlorhexidine in urine } \\
\text { expert: } 11 \text { factor reflected saturated factorial } \\
\text { expert system: idem }\end{array}$ \\
\hline 9 & $\begin{array}{l}\text { Chlorhexidine in guaze } \\
\text { expert: } 11 \text { factor reflected saturated factorial } \\
\text { expert system: idem }\end{array}$ \\
\hline 10 & $\begin{array}{l}\text { Aspirin and salicylic acid } \\
\text { expert: } 11 \text { factor reflected saturated factorial } \\
\text { expert system: idem }\end{array}$ \\
\hline 11 & $\begin{array}{l}\text { Halciderm cream preparation } \\
\text { expert: } 7 \text { factor reflected saturated factorial } \\
\text { expert system: idem }\end{array}$ \\
\hline
\end{tabular}

mented in an object-oriented way. This module is difficult to test because of the large number of possible interactions between the objects (in this case main effects). A number of test cases containing one main effect were generated. The test cases were generated as to contain main effects that appear during a regular consultation of the program. The test cases have been tested separately and in different combinations. In this way it was tested whether one main effect would be identified correctly by the program and whether more than one main effect would affect its performance. In Table 4 the simulated main effects are given. For 
each main effect it can be seen whether it resulted in a warning or a consultation of SOS.

The method improvement or SOS module, has been validated using 10 test cases selected from literature. As this module is of in nature algorithmic, the results of the test cases could also be calculated manually. However, the 'manual' calculation process is much more cumbersome than the

\section{TABLE 4}

Results of the test cases on the chemical results module

The following main effects were generated on concentration calculated with peak area :

$\begin{array}{lll}\text { Name } & \text { factor type } & \text { factor } \\ \text { SIM1.DAT } & \text { Sample preparation } & \text { SHAKE } \\ \text { SIM2.DAT } & \text { Chromatograph } & \text { PH } \\ \text { SIM3.DAT } & \text { Chromatograph } & \text { TEMP-CHROM } \\ \text { SIM4.DAT } & \text { Column } & \text { BATCH } \\ \text { SIM5.DAT } & \text { Column } & \text { MANUFAC } \\ \text { SIM6.DAT } & \text { Detector } & \text { WAVELENGTH } \\ \text { SIM7.DAT } & \text { Date handling } & \text { DATA-HAND }\end{array}$

and for concentration calculated with peak height there are :

$\begin{array}{llll}\text { SIM8.DAT } & \text { Chromatograph } & \text { FLOW-RATE } & 3 \% \\ \text { SIM9.DAT } & \text { Chromatograph } & \text { FLOW-RATE } & 7 \% \\ \text { SIM10.DAT } & \text { Chromatograph } & \text { PH } & 55 \%\end{array}$

for resolution :

SIM11.DAT

PH

Test schedule

\begin{tabular}{l||r|r|r|r|r|r|r|r|r|r|r} 
& 1 & 2 & 3 & 4 & 5 & 6 & 7 & 8 & 9 & 10 & 11 \\
\hline 1 & - & & & & & & & & & & \\
\hline 2 & - & - & & & & & & & & & \\
\hline 3 & $\operatorname{sos}$ & $\operatorname{sos}$ & $\operatorname{sos}$ & & & & & & & & \\
\hline 4 & - & - & $\operatorname{sos}$ & - & & & & & & & \\
\hline 5 & - & - & - & - & - & & & & & & \\
\hline 6 & - & - & - & - & - & - & & & & & \\
\hline 7 & - & - & - & - & - & - & - & & & & \\
\hline 8 & - & - & - & - & - & - & - & - & & & \\
\hline 9 & - & - & - & - & - & - & - & - & - & & \\
\hline 10 & - & - & - & - & - & - & - & - & - & - & \\
\hline 11 & - & sos & sos & - & - & - & - & - & - & sos & -
\end{tabular}

SOS = Tests wich resulted in a possible call to the SOS module.

$-=$ Tests wich resulted in a warning or advise other then the SOS consultation 
optimisation scheme programmed in the SOS module [2]. Because no better results could be obtained by other calculation procedures than those obtained using SOS, the validation of the module was thought to be successful. The results obtained with this module were found to be more accurate than the experimental accuracy that could be achieved in practice. The advice given by this module always provided the user with an improvement relative to the initial situation. However, experimental variations sometimes caused differences between the predictions of the system and subsequently recorded experimental data. More test cases will have to be put through the system in real laboratory situations to evaluate this module in practice.

The reselect factor levels module is basically a modified version of the factor choice module. It contains the rules that the factor choice module contains on the selection of levels. In the reselect factor levels module all level values are being changed. The outcome of the test cases that were used to test the factor choice module have been used to test this module. The factors selected by the factor choice module were entered and the new levels were compared with the old ones. In all of the test cases the expected levels were found.

\section{CONCLUSION}

In general, the RES program has yielded satisfactory results. All modules have been tested to perform with at least $80 \%$ success. In case of a disagreement it was often difficult to decide whether the system or the expert was wrong. RES is now ready to undergo testing in real laboratory environments.

The purpose of RES was to investigate the possibilities of expert systems in method validation in HPLC and similar areas. The conclusion from the work on RES is that expert systems can indeed be applied in areas such as chromatography. Their main benefit will be in the introduction of new techniques such as the ones used in chemometrics. Another beneficial application of expert systems can be found in the distribution of very specific chromatographic knowledge. Such knowl- edge can for instance be found at universities or dedicated routine laboratories. Incorporating this knowledge in an expert system can bring it to the attention of large numbers of potential users.

Based on our experience so far and reactions from chromatographers, it appears that HPLC is a very appropriate area for the application of expert systems. HPLC is a complex technique that requires relatively much method development work compared to other methods of analysis. Also, in HPLC method development many techniques are used arising from other fields of science (physics, mathematics). It is understandable that in an average laboratory not the entire scope of chromatography can be covered.

A typical disadvantage of expert systems is that they tend to be very expensive. Building a good expert system usually takes several years of work from both the expert and the knowledge engineer (the person building the system). However, considering the rate of progress in the development of knowledge acquisition tools, the development time may decrease considerably in the near future.

A second disadvantage of expert systems is the difficulty in motivating experts to contribute to such systems. This is understandable because experts themselves will profit from such systems only in the long term if their workload is reduced. However, experts need to be involved in building such systems from the beginning, and they are also asked questions on the more basic levels of their knowledge domain. A solution to this problem might be the use of system architectures as used for RES. The Common Data Structure in RES contains knowledge about basic HPLC equipment, procedures, etc. It contains the information that the expert will regard as trivial. It appears to be possible to build a Common Data Structure by consulting the expert on an infrequent basis, taking the knowledge from textbooks on the subject. The expert's specific knowledge can then be added to the system in the form of a module. Thus the expert involvement in building the system is reduced. Also, the present structure allows different modules to be obtained from the knowledge of different experts without serious conflict. Without the modular structure it would be necessary for the experts to decide on a com- 
mon approach to the problem at every level of detail. Such an expert versus expert confrontation may be both difficult and time-consuming. want to acknowledge J. Sommen and A. van Kampen for their contribution to writing the software.

\section{ACKNOWLEDGEMENT}

Part of this research is supported by the EC under Fsprit project 1570 ESCA. The authors

APPENDIX A

Screen dumps of a consultation of the system

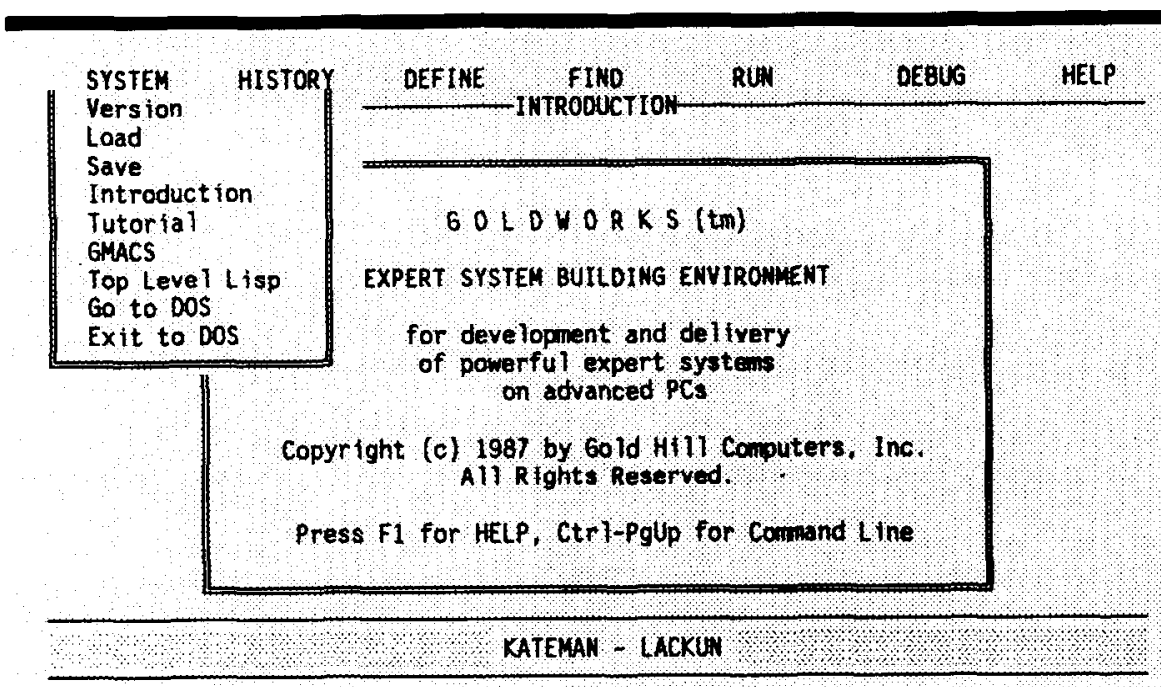

Go to 00 s and return to Golditorks

(C) 1987 GOLO HILL INC

A1 The introduction screen 
Screens $>$ Sample preparat lon quest tons $>$ opt ions

\section{SAMPLE PREPARATION 1}

Ma in quest tons and answers

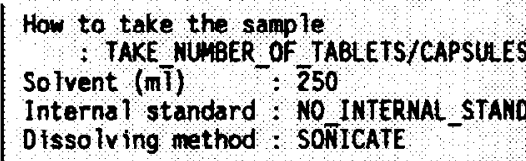

How to take the sample.

Solvent (mi),$\overline{250}$

Dissolving method 2 SOMICATE

\section{Related answers}

Samp te weight (mg)

Sample voliune (m)

Number of tablets

1

Shak Ing tine (min)

sonicate the (min)

Heat ing temperature (Deg C)

Internal std. wolit $(\mathrm{mg})$;

Internal Std. volume (m) )

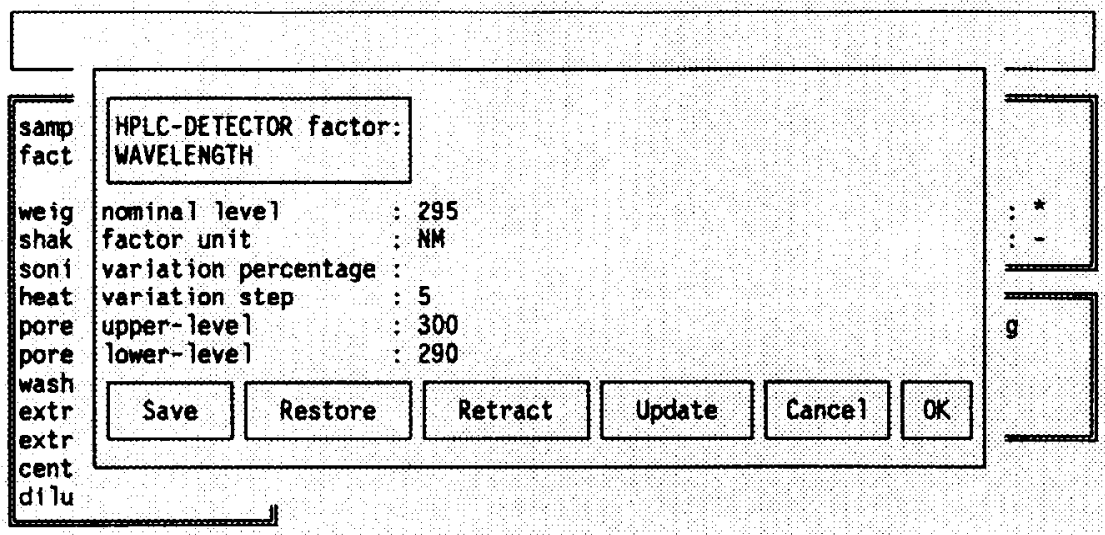

No modifications made 
$\rightarrow$ Options

\section{SELECTED EXPERTMEHTAL OESTGA}

Expertinental design \& REFLCTED-SATURATED F ACTORIAL_DESIGA

Divisor design $: 4$

Number of factors 7

Number of dumy factors : 0

Number of levels 3

Number of experlments $\quad 15$

\section{Store \\ Factor ldent if lat lon \\ Uavelength warning}

\section{A4 The design output window}

Used data files.

Output directory

Diagnose report file

Data file

Design flle

Conclusions dup lo differences ( $>2 \%$ )

Factors which were at extreme levels

Conclusions duplo differences $(1 X<<2 X)$

Conclusions factor effects lower level

Conclusions factor effects upper level

Systen suitability criteria

Average duplo's

Difference duplo's

Standard errors

Ma in effects lower level

Main effects upper level

Cance?

$$
\text { OK. }
$$

C:Igmlantainelpart5

- report.prn

- aspusa 1 exp

t c. Igulantoine lpart5/dsgirsfo7, ds

- seout2. dat

i exfac.dat

- seout12, dat

- concl. dat

- conc2, dat

s ssc, dat

- aver dat

olff. dat

- std. dat

- mal dat

- me2.dat 
* Screens > Conclusions > Explanation respectf icat ion

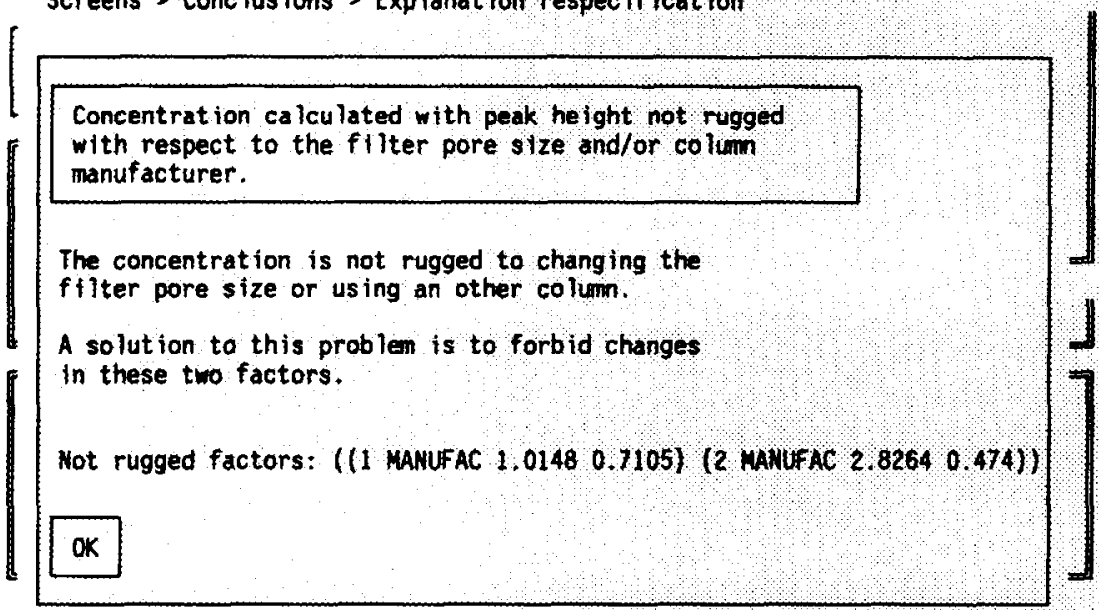

[Respecify all factors : - -

\section{A6 Conclusion about a concentration main effect}

Screens > Explanation

User advise warning message's

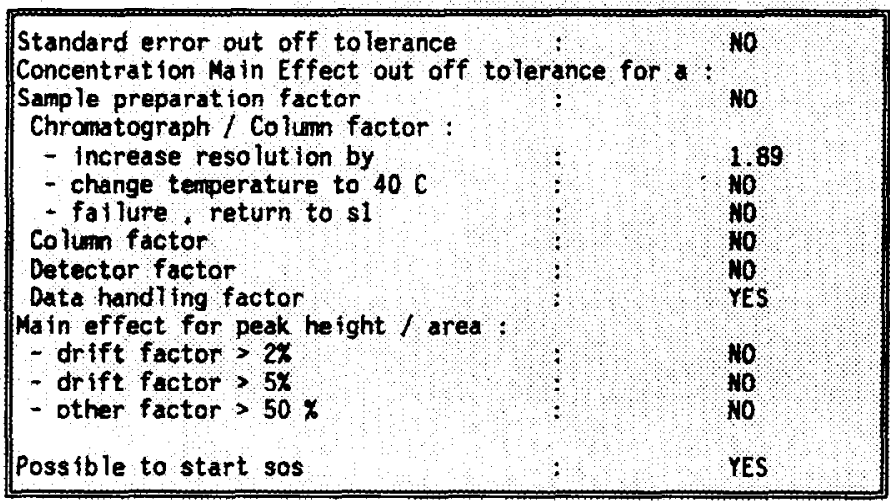

\section{A7 The sos screen with input and output values}


- Screens $>$ Conclustons $>$ Explanation respectification

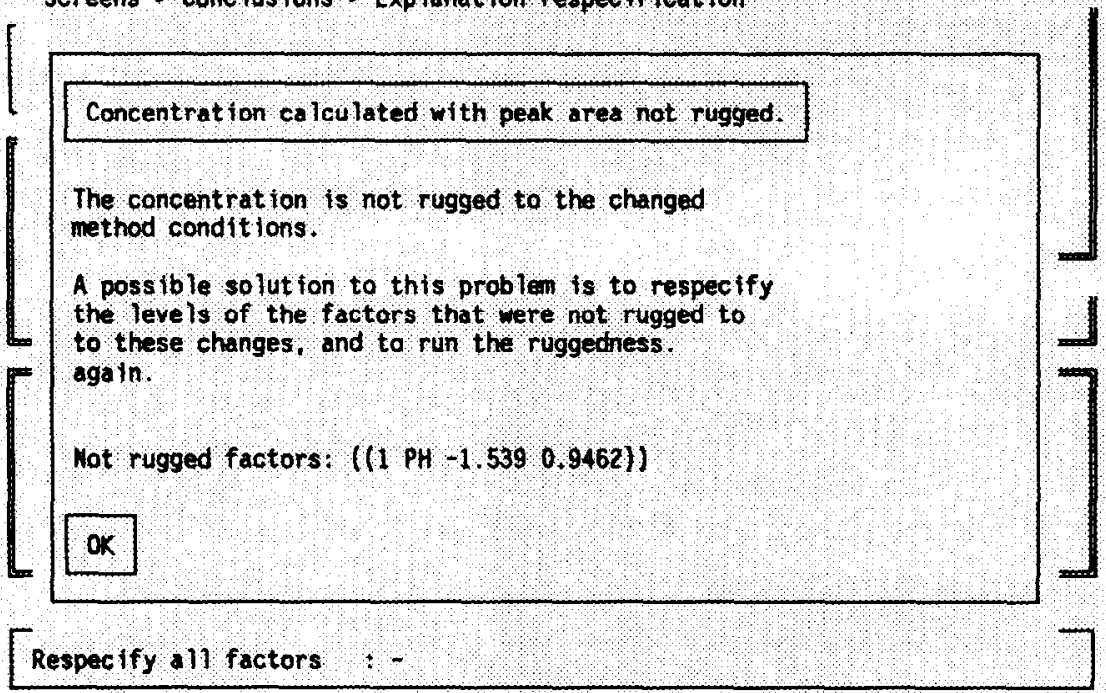

A8 The diagnosis output screen filled with some problems 


\section{APPENDIX B}

\section{Test case results on the factor choice module}

Possible factors:

Sample preparation factors

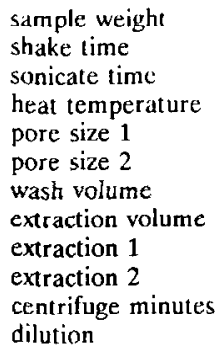

Calibration preparation factors

weight

shake time

sonicate time

heat temp

dilution

centrifuge minutes

Datahandling factors:

19 user selected factor

Chromatograph factors:

pH

temperature

buffer concentration

solvent $\%$

additive concentralion

flow rate

\section{Column factors:}

26 manufacturer

27 batch

Delcctor factors:

ri-range

filter

wavelength

uv time constant

ri time constant

Icsicase sample name

Salbulamol

factors selected by expert: $\quad 2,5,19,20,21,23,26,30,31$ factors selected by expert system: $2,19,20,21,23,24,26,30,31$ \# of same faclors: 8

expert systems's factor choice acceptable: yes

2

factors selected by expert: $\quad 21,23,24,27$

factors selected by expert systim: 20, 21, 22, 23, 24, 27

\# of sante faciors: 4

expert systems's facior choice acceptable: no

Fat soluble vitamin

factors selected by expert: $\quad 9,23,25,30$

factors selected by expert system: $3,9,23,25,31$

\# of same factors:

3

expert systems's factor choice acceptable: yes

4

Steroids by fast $L C$

factors selected by expert: $\quad 5,19,21,24,25,26,30,31$ factors selected by expert system: 19, 21, 23, 24, 25, 26, 30 \# of same factors: 6

expert systcms's factor choice acceptable: yes

factors selected by expert: $\quad 9,10,21,24,27,30$

factors selected by expert system:9, 10, 21, 23, 24

\# of same factors: 4

expert systems's factor choice acceptable: yes

6

Contraceptive tablet

factors selected by expert: $19,21,23,26,30$

factors selected by expert systen: 19, 21, 23, 26, 30, 31

\# of same factors

expert systems's lactor choice acceptable: yes

factors selected by expert:

Anti inflammatory drugs

$\quad 19,21,23,24,26,30$

factors selected by expert system: 19,21, 23, 26, 30

\# of same factors:

5

expert systems's factor choice acceptable: yes

Chlorhexidinc in urine

factors selected by expert: $\quad 7,8,19,20,23,24,26,30$

factors selected by expert system: $7,8,19,20,22,23,24,26,30$

\# of same factors: 7

expert systems's factor choice acceptable: yes

factors selected by expert: $\quad 7,19,23,24,25,26,30,31$ factors selected by expert system: $1,19,22,23,24,25,26,31$

\# of same faciors: 6

expert systems's factor choice acceptable: yes

Aspirin and salicylic acid

factors selected by expert: $\quad 3,5,19,20,21,23,26,30$

factors selectcd by expert systcm. 3, 5, 19, 20, 23, 26, 30

\# of same factors.

expert syslems's factor choice acceplable; yes
Halciderm cream preparation

factors selectcd by experi: $2,19,21,23,26,30$

factors selected by expert system: $2,5,19,21,23,26,30$

\# of same factors: 6

expert systems's factor choice acceptable: yes 


\section{REFERENCES}

1 J.A. van Leeuwen, L.M.C. Buydens, B.G.M. Vandeginste, G. Kateman, P.J. Schoenmakers and M. Mulholland, RES, an expert system for the set-up and interpretation of a ruggedness test in HPLC method validation. Part 1: The ruggedness test in HPLC method validation, Chemometrics and Intelligent Laboratory Systems, 10 (1991) 337-347.

2 P.J. Schoenmakers, N. Dunand, A. Cleland, G. Musch and T. Blaffert, An expert system for the optimization of columns, operating conditions and instrumentation for high pressure liquid chromatography, Chromatographia, 26 (1988) 37-44.

3 A. Peeters, L. Buydens, D.L. Massart and P.J. Schoenmakers, An expert system for the selection of criteria for selectivity optimization in high-pressure liquid chromatography, Chromatogrophia, 26 (1988) 101-109.

4 L.M.C. Buydens, J.A. van Leeuwen, M. Mulholland, B.G.M. Vandeginste and G. Kateman, An expert system for the validation of high-performance liquid chromatographic methods, Trends in Analytical Chemistry, 7 (1990) 58-62.

5 N.A.B. Gray, Artificial intelljgence in chemistry, Analytica Chimica Acta, 210 (1988) 9-32.

6 L. Buydens, A. Peeters and D.L. Massart, Knowledge representation for the selection of methods in analytical chemistry, Chemometrics and Intelligent Laboratory Systems, 5 (1988) 73-79.

7 L. Buydens, D.L. Massart and P.K. Hopke, Evaluation of the expert system shells EX-TRAN and TIMM as rulebuilding tools for classification purposes, Chemometrics and Intelligent Laboratory Systems, 3 (1988) 199-204.

8 M.A. Tischler and A.F. Fox, An expert system for selecting liquid chromatographic separation methods, Computers in Chemistry, 11 (1987) 235-240.

9 M. Bos, E. Hoogendam and W.E. van der Linden, A knowledge based system for the automatic chronopotentiometric elucidation of electrode reaction mechanisms, Analytica Chimica Acta, 211 (1988) 61-73.

10 D. Betteridge, R. Mackison, C.M. Motterhead, A.F. Taylor and A.P. Wade, Development of an expert system for the selection of sample points for moisture analysis, Analytical Chemistry, 58 (1988) 1534-1539.

11 H. Gunasingham, B. Srinivasan and A.L. Ananda, Design of a Prolog-based expert system for planning separations of steroids by high performance liquid chromatography, Analytica Chimica Acta, 182 (1986) 193-202.

12 K. Janssens and P. Van Espen, Analysis of energy dispersive X-ray spectra with the aid of expert systems, Analytica Chimica Acta, 191 (1986) 169-180.

13 S. Moldoveanu and C.A. Rapson, Spectral interpretation for organic analysis using an expert system, Analytical Chemistry, 59 (1987) 1207-1212.

$14 \mathrm{~K}$. Janssens and P. Van Espen, Implementation of an expert system for the automated qualitative interpretation of energy dispersive X-ray spectra, Analytica Chimica Acta, 184 (1986) 117-132.

15 G.J. Kleywegt, H.J. Luinge and H.A. van 't Klooster, Artificial intelligence used for the interpretation of combined spectral data, Part II. PEGASUS: a Prolog program for the generation of acyclic molecular structures, Chemometrics and Intelligent Laboratory Systems, 2 (1987) 291302.

16 P. Edwards and P.B. Ayscough, A cooperative approach to the structure elucidation problem, Chemometrics and Intelligent Laboratory Systems, 5 (1988) 81-93.

17 K. Janssens, W. Dorrine and P. Van Espen, The development process of an expert system for the automated interpretation of large EPMA data sets, Chemometrics and Intelligent Laboratory Systems, 4 (1988) 147-161.

18 C.G. Enke, A.P. Wade, P.T. Palmer and K.J. Hart, Strategies for automated structure elucidation, Analytical Chemistry, 59 (1987) 1363-1371.

19 R. Wulkan, Liem, Zwang, Blijenberg, LITHOS, an expert system for evaluation of $\mathrm{X}$-ray diffractograms of urinary calculi, Journal of Clinical Chemistry and Clinical Biochemistry, 25 (1987) 719-722.

20 L.S. Ying, S.A. Tomellini and S.R. Lowry, Self-training, self-optimising expert system for interpretation of the infrared spectra of environmental mixtures, Analytical Chemistry, 59 (1987) 2197-2203.

21 L.S. Ying, S.P. Levine, S.A. Tomellini and S.R. Lowry, Expert system for interpretation of the infrared spectra of environmental mixtures, Analytica Chimica Acta, 210 (1988) 51-63.

22 M.A. Puskar, S.P. Levine and S.R. Lowry, Computerized infrared spectral identification of compounds frequently found at hazardous waste sites, Analytical Chemistry, 58 (1986) 1156-1162.

23 M.A. Puskar, S.P. Levine and S.R. Lowry, Infrared screening techniques for automated identification of bulk organic mixtures, Analytical Chemistry, 58 (1986) 1981-1988.

24 J.A. van Leeuwen, B.G.M. Vandeginste, G. Kateman, M. Mulholland and A. Cleland, An expert system for the choice of factors for a ruggedncss test in liquid chromatography, Analytica Chimica Acta, 228 (1990) 145-153.

25 S.N. Deming and S.L. Morgan, Experimental Design: $A$ Chemometric Approach, Elsevier, Amsterdam, 1987.

26 D.L. Massart, B.G.M. Vandeginste, S.N. Deming, Y. Michotte and L. Kaufman, Chemometrics: A Textbook, Elsevier, Amsterdam, 1988.

27 M. Mulholland, J.A. van Leeuwen and L. Buydens, The evaluation of an expert system for method validation, Journal of Chromatography, in press.

28 ANSI/IEEE std. 829-1983, Software Test Documentation, Wiley-Interscience, New York, 1983. 